\title{
The diagnosis of clinically significant oesophageal Candida infections: a reappraisal of clinicopathological findings
}

\author{
Erika Hissong, ${ }^{1}$ iD Shula Schechter, ${ }^{2}$ Jonathan Mowers, ${ }^{2}$ Rhonda K Yantiss, ${ }^{1}$ Tomas Slavik, ${ }^{3}$ \\ Jerome Cheng ${ }^{2}$ \& Laura W Lamps ${ }^{2}$ \\ ${ }^{1}$ Department of Pathology and Laboratory Medicine, Weill Cornell Medicine, New York, NY, ${ }^{2}$ Department of Pathology, \\ University of Michigan, Ann Arbor, MI, USA, and ${ }^{3}$ Ampath Pathology Laboratories, University of Pretoria, Pretoria, \\ South Africa
}

Date of submission 14 November 2019

Accepted for publication 10 January 2020

Published online Article Accepted 15 January 2020

Hissong E, Schechter S, Mowers J, Yantiss R K, Slavik T, Cheng J \& Lamps L W.

(2020) Histopathology 76, 748-754. https://doi.org/10.1111/his.14063

\section{The diagnosis of clinically significant oesophageal Candida infections: a reappraisal of clin- icopathological findings}

Aims: Distinguishing true oesophageal Candida infections from oral contaminants is a common diagnostic issue. Historically, histological features believed to indicate true infection included epithelial invasion by pseudohyphae and intraepithelial neutrophils. Whether or not these features correlate with endoscopic lesions, symptoms and response to therapy has never been tested in a large cohort. The aim of this study was to determine whether specific histological features correlate with clinical and endoscopic findings when Candida is found in oesophageal biopsies.

Methods and results: We reviewed 271 biopsies in which Candida was detected. Cases were evaluated for the presence of desquamated epithelial cells, location/type of fungal forms, neutrophils, and ulceration. Medical records were reviewed for clinical history, endoscopic lesions, and response to antifungal therapy. Statistical analysis was used to determine whether any histological features significantly correlated with

Keywords: Candida, infection, oesophagitis clinical variables. There were 120 males and 151 females with a mean age of 42 years. Fifty-nine per cent had symptoms referable to the oesophagus, particularly dysphagia (36\%). Most (73\%) patients had abnormal endoscopic findings, with plaques, ulcers, or macroscopic evidence of oesophagitis. Seventy-one per cent of patients with documented antifungal therapy showed symptomatic improvement. Overall, there was no statistically significant correlation between any histological feature and presenting symptoms, endoscopic findings, or response to therapy. Importantly, the lack of pseudohyphae, demonstrable invasion of intact epithelium or neutrophilic infiltrates did not exclude clinically significant infection.

Conclusions: We conclude that detection of Candida in oesophageal biopsies is always potentially clinically significant. Treatment decisions should be made on the basis of an integration of clinical, endoscopic and histological findings.

\section{Introduction}

Infectious oesophagitis is the third leading cause of oesophagitis, following gastro-oesophageal reflux and eosinophilic oesophagitis. ${ }^{1} \quad$ Candida infection, particularly with Candida albicans, is the most common cause of infectious oesophagitis, with an overall prevalence of $0.8-7.3 \%{ }^{2-11}$ Candida is generally considered to cause an opportunistic infection, resulting in disease in patients with altered immunity due to 
immunodeficiency, diabetes mellitus, pregnancy, advanced age, and a number of other disorders associated with alterations in the normal components of the gastrointestinal flora. Affected patients typically present with odynophagia and/or dysphagia accompanied by endoscopically apparent white plaques and exudates; ulcers and strictures can occur in severe cases. $^{2,3,11-13}$ Although exudates are fairly characteristic of oesophageal candidiasis, they are not uniformly present in infected patients, and nor are they entirely specific for this diagnosis. In fact, the specificity of upper endoscopic findings for Candida oesophagitis is only slightly more than $80 \%$, with a positive predictive value of $89 \% .^{14}$ For this reason, definite diagnosis relies on pathological confirmation with cytological brushings, mucosal biopsy, and, in some cases, fungal cultures.

Oropharyngeal colonisation by Candida occurs in $31-60 \%$ of healthy individuals, with highest rates among those with comorbidities, recent antibiotic use, and underlying malignancy. ${ }^{15-18}$ Distinction between true oesophageal infection and contaminants from colonised oropharyngeal mucosa is clinically important, and several histological findings have been passed down through generations of trainees as indicators of clinically significant oesophageal infection. These include the presence of pseudohyphae, epithelial invasion by fungi, and detection of intraepithelial neutrophils, particularly when clustered in the superficial epithelium. ${ }^{7,11,19}$ However, the significance of these histological features has never been rigorously evaluated in a systematic fashion, and nor has there been any attempt to correlate, in a large cohort, their presence or absence with clinical symptoms, endoscopic lesions, or response to antifungal therapy. We performed this study to determine whether any specific histological features are correlated with clinical symptoms, underlying conditions, endoscopic findings or treatment response when oesophageal samples contain Candida.

\section{Materials and methods}

C A S E SELECTION

We retrospectively identified oesophageal biopsy samples containing Candida from three participating institutions located on the east coast of the USA, in the midwestern USA, and in South Africa. The electronic medical records and endoscopy reports of 271 patients were reviewed for information regarding comorbidities, presenting symptoms, endoscopic findings, therapeutic interventions, and follow-up data, when available. Permission for the study was obtained from the Institutional Review Boards of each of the participating groups.

\section{H I S T P A THOLOGICAL EV ALU A T I N}

Routinely processed, haematoxylin and eosin (H\&E)stained tissue sections from all cases were evaluated by a pathologist at each institution. Each case was assessed for specific histological features that were defined and agreed upon by all participating reviewers. These included the presence of desquamated epithelial cells and/or keratin debris, reactive epithelial changes (i.e. basal cell hyperplasia, rete peg elongation, and intercellular oedema), location of fungi in intact epithelium or desquamated debris, morphology of fungal forms (i.e. budding yeast and/or pseudohyphae), the presence of neutrophils in the intact epithelium, and ulceration. When available, Gomori methenamine-silver nitrate and/or periodic acidSchiff-diastase stains were reviewed, but the determination of the presence or absence of Candida was made on H\&E-stained sections. Histological findings were compared with clinical and endoscopic findings as well as treatment and outcome data.

\section{STATISTICAL ANALYSIS}

Fisher's exact test was used to evaluate the associations between clinical and histological features. Associations with a $P$-value of $<0.05$ were considered to be statistically significant. All analyses were conducted with JMP, Version 14.1 (SAS Institute, Cary, $\mathrm{NC}, \mathrm{USA}$ ).

\section{Results}

The study group consisted of 271 biopsy samples from individual patients, comprising 120 males and 151 females. Most patients were adults, with a mean age of 42 years (range, 1-91 years). Clinical and endoscopic features are summarised in Table 1. Approximately half $(48 \%)$ of the study patients had underlying conditions predisposing them to Candida infection, most commonly autoimmune diseases $(n=51,19 \%)$ managed with immunosuppressive therapy, followed in frequency by concurrent cancer (14\%) and diabetes mellitus (11\%). Most (59\%) patients presented with oesophageal symptoms, particularly dysphagia (36\%). Thirteen (5\%) patients complained of odynophagia, and 103 (38\%) showed no symptoms directly referable to the oesophagus. 
The majority $(n=199,73 \%)$ of patients had abnormal endoscopic examination findings, with plaques, ulcers, or macroscopic evidence of oesophagitis (Figure 1). The frequency of endoscopic abnormalities did not differ between patients with and without symptoms. Therapeutic interventions with antifungal therapy were documented in $209(77 \%)$ patients. Of these, $149(71 \%)$ experienced complete resolution of symptoms or symptomatic improvement after treatment with antifungal agents. Candida infection was superimposed on a pre-existing or concurrent oesophageal disease in a minority $(\sim 30 \%)$ of patients. The most common coexisting oesophageal disease was a history of reflux (24\% of all patients). Twenty patients with both Candida infection and a history of reflux were treated with antifungals; of those, $45 \%$ responded to antifungal therapy, and only two had simultaneous changes made to their anti-reflux therapy dosage. Thus, for at least the vast majority of cases, symptom resolution, when documented, clinically appeared to be due to antifungal therapy.

The histological features of the study cases are shown in Table 2. Desquamated epithelial cells $(n=243,90 \%)$ and pseudohyphae $(n=262,96 \%)$ were most commonly detected (Figure 2). Ulcers and/ or erosions were identified in $41(15 \%)$ cases. Invasive yeast was observed in intact squamous epithelium in $100(37 \%)$ cases, but this feature did not significantly correlate with the presence of clinical symptoms or any endoscopic findings. The only histological findings that were associated with the presence of clinical symptoms were reactive epithelial changes, including basal cell hyperplasia, rete peg elongation, and/or intercellular oedema, which are findings similar to those made in reflux-related injury $(78 \%, \quad P=0.01)$. Similarly, reactive epithelial changes constituted the only histological parameter that showed a statistically significant association with endoscopy findings or response to treatment. Moreover, there was no relationship between the histological identification of epithelial invasion by fungi and a clinical response to antifungal agents (Figure 2). In fact, $64 \%$ of patients with a documented response to antifungal therapy did not have fungal invasion of the epithelium in their biopsy samples. Only nine (4\%) patients had biopsy samples that featured budding yeast without pseudohyphae. Six of these patients had oesophageal symptoms accompanied by endoscopically apparent plaques $(n=3)$, ulcers $(n=1)$, and oesophagitis $(n=2)$, including five patients who experienced symptomatic relief with antifungal therapy. The relationships between histological findings, presenting oesophageal symptoms,
Table 1. Clinical features of patients with Candida oesophagitis

\begin{tabular}{|c|c|}
\hline & Total patients $(N=271)$ \\
\hline Mean age (years) & 42 (range: 1-91) \\
\hline Male/female ratio & $120: 151$ \\
\hline \multicolumn{2}{|l|}{ Comorbidities, $n(\%)$} \\
\hline Cancer & $38(14)$ \\
\hline Autoimmune disease & $51(19)$ \\
\hline Immunosuppressive therapy & $43(16)$ \\
\hline Transplant & $16(6)$ \\
\hline HIV & $10(4)$ \\
\hline $\mathrm{HCV}$ & $6(2)$ \\
\hline Diabetes & $31(11)$ \\
\hline \multicolumn{2}{|l|}{ Indication for endoscopy, $n(\%)$} \\
\hline Abdominal pain & $37(14)$ \\
\hline Dysphagia & $97(36)$ \\
\hline Oesophageal reflux & $47(17)$ \\
\hline Anaemia & $18(7)$ \\
\hline Barrett's disease & $11(4)$ \\
\hline Odynophagia & $13(5)$ \\
\hline Bleeding & $12(4)$ \\
\hline Follow-up (other) & $17(6)$ \\
\hline Nausea/vomiting & $17(6)$ \\
\hline
\end{tabular}

HCV, Hepatitis C virus; HIV, Human immunodeficiency virus.

endoscopic abnormalities and documented response to antifungal treatment are summarised in Table 3.

\section{Discussion}

To our knowledge, this is the first study of its size that has tested widely held notions regarding the clinical significance of various histological findings encountered in oesophageal samples harbouring Candida, and has reassessed the diagnostic criteria for oesophageal candidiasis. We did not find any correlations between specific histological features and presenting symptoms or comorbidities, endoscopic findings, or response to antifungal therapy. Importantly, the lack of pseudohyphae or demonstrable invasion of intact epithelium, long touted as morphological indicators of 'true' Candida infection, did not exclude the possibility of 


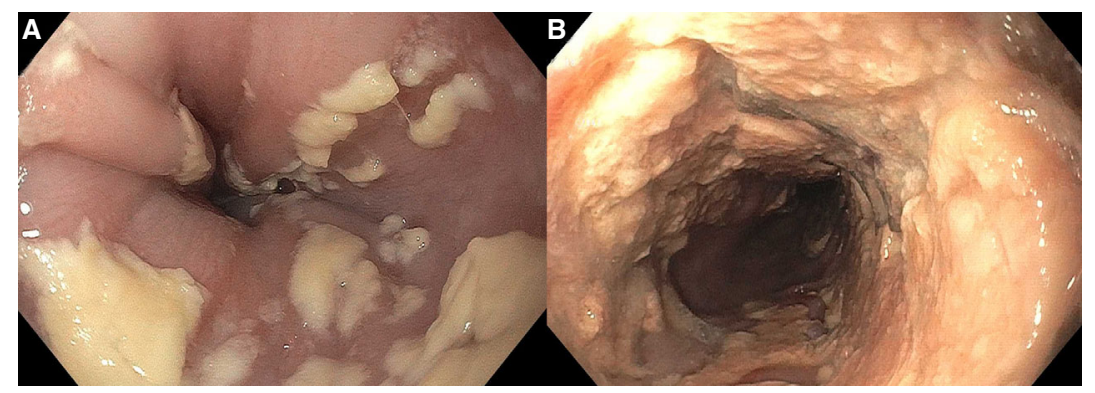

Figure 1. Most patients with abnormal endoscopic findings had yellow-white exudates in a focal (A) or a diffuse, circumferential distribution; the latter were frequently associated with ulcers (B).

Table 2. Histological findings in all oesophageal biopsies with Candida

\begin{tabular}{|c|c|}
\hline Histological findings & $\begin{array}{l}\text { All biopsies }(N=271), n \\
(\%)\end{array}$ \\
\hline Presence of budding yeast & $219(81)$ \\
\hline Epithelial neutrophilic infiltrate & $184(68)$ \\
\hline Yeast in intact squamous epithelium & $100(37)$ \\
\hline Presence of pseudohyphae & $262(96)$ \\
\hline $\begin{array}{l}\text { Desquamated epithelial cells and } \\
\text { keratin }\end{array}$ & $243(90)$ \\
\hline Reactive epithelial changes & $195(72)$ \\
\hline Ulceration & $41(15)$ \\
\hline
\end{tabular}

clinically significant oesophageal infection. Six (4\%) of our study patients experienced symptomatic relief with antifungal therapy even though their biopsy samples contained only budding yeast and/or lacked invasive fungi in the epithelium. We conclude that detection of fungal forms in oesophageal biopsy material should always be considered as being potentially clinically significant. In other words, pathologists should not disregard isolated budding yeast in detached debris as oral contamination, and nor should they require the presence of neutrophilic inflammation to establish a diagnosis of fungal infection. In fact, only slightly over half of the biopsies $(68 \%)$ included in this study contained a neutrophilic infiltrate, and $23 \%$ of biopsies with demonstrable invasion of mucosa did not have associated neutrophils. Interestingly, patients with neutrophils were more likely to be immunosuppressed, most commonly because of an autoimmune condition.

Candida oesophagitis is an important cause of morbidity, particularly among immunocompromised patients. Although this disease once showed a predilection for human immunodeficiency virus- infected individuals and developed in up to $42 \%$ of these patients, improved retroviral therapy has resulted in decreased infection rates in this population. $^{20}$ Other risk factors for Candida oesophagitis include heavy alcohol consumption, hepatitis C viral infection, syphilis, and medications such as corticosteroids, non-steroidal anti-inflammatory drugs, acetaminophen, and proton pump inhibitors. ${ }^{6}$ Recent use of antibiotic agents, motility disorders, uncontrolled diabetes mellitus, malnutrition and any process that diminishes host immunity, alters $\mathrm{pH}$ or modifies the microbial flora of the mucous membranes can also predispose to oesophageal candidiasis. ${ }^{1,3,5,14-16,21}$

The mainstay of therapy for Candida oesophagitis is oral fluconazole, with resolution rates of $>90 \%$ in treated patients. ${ }^{10,21-26}$ However, emerging data suggest that not all patients require therapeutic intervention. $^{27,28}$ Lee et al. evaluated 141 asymptomatic patients with Candida oesophagitis, and found that $81 \%$ showed resolution of oesophageal inflammation on follow-up endoscopy, even though most were not treated with antifungal therapy. ${ }^{28}$ Hoversten et al. reported similar findings. In their study of 218 patients with Candida in oesophageal biopsy samples, $92 \%$ of untreated patients showed resolution of lesions at interval endoscopy. Of the 74 asymptomatic patients who did not receive a therapeutic intervention, most $(91 \%)$ remained asymptomatic, and all patients $(n=12)$ who underwent follow-up endoscopy showed resolution of oesophageal inflammation. ${ }^{29}$ Although these data suggest that asymptomatic Candida oesophagitis is of little clinical significance in some patients, criteria for distinguishing patients who require therapy from those who do not remain unclear; asymptomatic patients can certainly have endoscopically apparent oesophagitis with exudates and fungi in oesophageal biopsy samples. Oesophageal biopsies with Candida are usually described as containing budding yeast and/or pseudohyphae, variably 


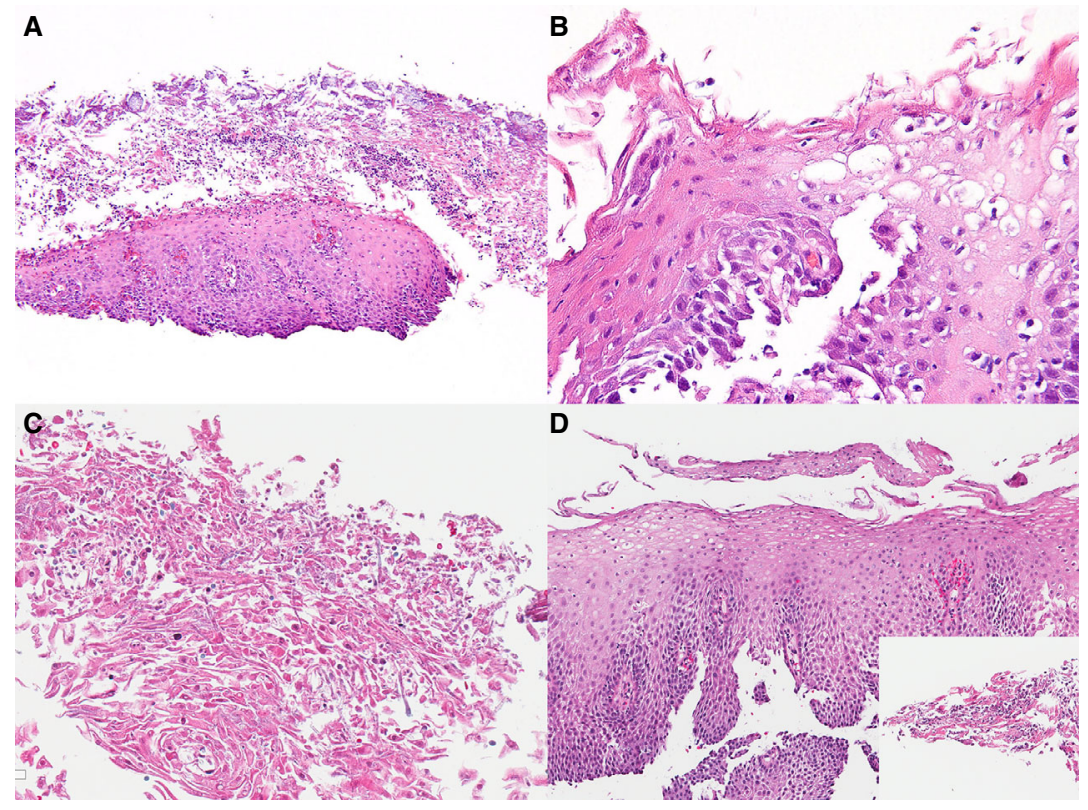

Figure 2. Samples from four symptomatic patients with endoscopically identified oesophageal plaques and a response to antifungal therapy feature variably severe abnormalities. Some cases featured squamous hyperplasia with intraepithelial neutrophils, desquamation, and budding yeast with pseudohyphae in both desquamated and intact epithelium (A). Others featured superficially invasive yeast unaccompanied by inflammation (B). Some patients with yeast confined to desquamated keratin debris responded to antifungal therapy (C). Another patient with endoscopically apparent plaques had mostly unremarkable squamous mucosa (D); a few budding yeast without pseudohyphae were limited to desquamated epithelium (see inset).

Table 3. Histological findings in oesophageal biopsies of symptomatic patients, those with endoscopic abnormalities, and/or those who responded to antifungal therapy

\begin{tabular}{|c|c|c|c|}
\hline Histological findings & $\begin{array}{l}\text { Symptomatic } \\
\text { patients } \\
(N=157), \\
n(\%)\end{array}$ & $\begin{array}{l}\text { Endoscopic } \\
\text { abnormalities } \\
\text { present } \\
(N=199) \\
n(\%)\end{array}$ & $\begin{array}{l}\text { Response to } \\
\text { antifungal } \\
\text { treatment } \\
(N=149) \text {, } \\
n(\%)\end{array}$ \\
\hline $\begin{array}{l}\text { Presence of } \\
\text { budding yeast }\end{array}$ & $126(80)$ & $159(80)$ & $117(79)$ \\
\hline $\begin{array}{l}\text { Epithelial neutrophilic } \\
\text { infiltrate }\end{array}$ & $114(73)$ & $142(71)$ & $94(63)$ \\
\hline $\begin{array}{l}\text { Yeast in intact } \\
\text { squamous epithelium }\end{array}$ & $60(38)$ & $76(38)$ & $53(36)$ \\
\hline $\begin{array}{l}\text { Presence of } \\
\text { pseudohyphae }\end{array}$ & $151(96)$ & $192(96)$ & $133(89)$ \\
\hline $\begin{array}{l}\text { Desquamated epithelial } \\
\text { cells and keratin }\end{array}$ & $143(91)$ & $184(92)$ & $125(84)$ \\
\hline $\begin{array}{l}\text { Reactive epithelial } \\
\text { changes* }\end{array}$ & $122(78)$ & $152(76)$ & $126(85)$ \\
\hline Ulceration & $25(16)$ & $25(13)$ & $22(15)$ \\
\hline
\end{tabular}

*This was the only histological finding that showed a statistically significant association with clinical symptoms $(P=0.013)$, endoscopic abnormalities $(P=0.035)$, or response to antifungal treatment $(P=0.014)$. present neutrophilic and/or lymphocytic infiltrates, superficial exudates of desquamated epithelial cells, and reactive squamous epithelial changes that may mimic other types of oesophagitis. ${ }^{5,19,30}$ Historically, many pathologists have required the presence of pseudohyphae and/or fungal invasion of intact epithelium to establish a diagnosis of clinically significant infection, but our data show that patients with clinically significant infections often lack these features. In addition, desquamated tissue fragments and detached yeast may be lost as a result of prior cytological brushings or during tissue processing. ${ }^{11,31}$ In these situations, other histological changes, such as reactive epithelial changes or intraepithelial neutrophils, may be helpful diagnostic clues. ${ }^{2,30,32}$ However, approximately one-quarter of the patients in our study had oesophageal biopsies that showed fungal invasion of the squamous epithelium unaccompanied by neutrophil-rich inflammation.

The results of this study indicate that the histological features of oesophageal Candida infection are variable and do not correlate well with either clinical or endoscopic findings. They also suggest that the historical question regarding the distinction of clinically significant infection from oral flora is probably not within the sole purview of pathologists. Our data show that detection of Candida is rarely a clinically 
insignificant finding, even if only budding yeast is identified in oesophageal biopsy samples. For this reason, pathologists should determine whether yeast is present in oesophageal biopsy samples, but they cannot confirm or exclude clinically significant Candida infection, particularly among immunocompromised patients. The ultimate decision to treat Candida infection with antifungal therapy should be made on the basis of the integration of clinical, endoscopic and histological findings.

\section{Conflicts of interest}

None of the authors has a conflict of interest to disclose.

\section{Funding}

As this research was a morphological study involving retrospective review of H\&E-stained slides, no additional funding was required.

\section{Author contributions}

E. Hissong performed the research for institutional cases, and wrote the manuscript. S. Schechter performed Electronic Medical Records review for institutional cases. J. Mowers analysed the data (statistical analysis). R. K. Yantiss designed the research study, and wrote and edited the manuscript. T. Slavik performed the research for institutional cases. J. Chang performed case cohort identification for institutional cases. L. W. Lamps designed the research study, and wrote and edited the manuscript.

\section{References}

1. Hoversten P, Kamboj AK, Katzka DA. Infections of the esophagus: an update on risk factors, diagnosis, and management. Dis. Esophagus 2018; 31; 1-9.

2. Yakoob J, Jafri W, Abid S et al. Candida esophagitis: risk factors in non-HIV population in Pakistan. World J. Gastroenterol. 2003; 9; 2328-2331.

3. Underwood JA, Williams JW, Keate RF. Clinical findings and risk factors for Candida esophagitis in outpatients. Dis. Esophagus 2003; 16; 66-69.

4. Weerasuriya N, Snape J. A study of Candida esophagitis in elderly patients attending a district general hospital in the UK. Dis. Esophagus 2006; 19; 189-192.

5. Kodsi BE, Wickremesinghe PC, Kozinn PJ, Iswara K, Goldberg PK. Candida esophagitis: a prospective study of 27 cases. Gastroenterology 1976; 71; 715-719.

6. Takahashi Y, Nagata N, Shimbo T et al. Long-term trends in esophageal candidiasis prevalence and associated risk factors with or without HIV infection: lessons from an endoscopic study of 80,219 patients. PLoS ONE 2015; 10; e0133589.

7. Wilcox CM, Karowe MW. Esophageal infections: etiology, diagnosis, and management. Gastroenterologist 1994; 2; 188-206.

8. O'Rourke A. Infective oesophagitis: epidemiology, cause, diagnosis and treatment options. Curr. Opin. Otolaryngol. Head Neck Surg. 2005; 23; 459-463.

9. Baehr PH, McDonald GB. Esophageal infections: risk factors, presentation, diagnosis, and treatment. Gastroenterology 1994; 106; 509-532.

10. Wilcox CM. Overview of infectious esophagitis. Gastroenterol. Hepatol. 2013; 9; 517-519.

11. Mathieson R, Dutta S. Candida esophagitis. Dig. Dis. Sci. 1983; 28; 365-370.

12. Mimidis K, Papadopoulos V, Margaritis V et al. Predisposing factors and clinical symptoms in HIV-negative patients with Candida oesophagitis: are they always present? Int. J. Clin. Pract. 2005; 59; 210-213.

13. Mushi MF, Ngeta N, Mirambo MM, Mshana SE. Predictors of esophageal candidiasis among patients attending endoscopy unit in a tertiary hospital, Tanzania: a retrospective cross-sectional study. Afr. Health Sci. 2018; 18; 66-71.

14. Redah D, Konutse AY, Agbo K et al. Is endoscopic diagnosis of Candida albicans esophagitis reliable? Correlations with pathology and mycology. Gastroenterol. Clin. Biol. 2001; 25; 161163.

15. Kleinegger CL, Lockhart SR, Vargas K, Soll DR. Frequency, intensity, species, and strains of oral Candida vary as a function of host age. J. Clin. Microbiol. 1996; 34; 2246-2254.

16. Johnston RD, Chick EW, Johnston NS, Jarvis MA. Asymptomatic quantitative increase of candida albicans in the oral cavity: predisposing conditions. South. Med. J. 1967; 60; 1244-1247.

17. Vazquez JA. Candidiasis. In Dismukes W, Pappas PG, Sobel JD eds. Clinical mycology. New York: Oxford University Press, 2003: 143-187.

18. Gammelsrud KW, Sandven P, Høiby EA, Sandvik L, Brandtzaeg P, Gaustad P. Colonization by Candida in children with cancer, children with cystic fibrosis, and healthy controls. Clin. Microbiol. Infect. 2011; 17; 1875-1881.

19. Alsomali MI, Arnold MA, Frankel WL et al. Challenges to 'classic' esophageal candidiasis: looks are usually deceiving. Am. J. Clin. Pathol. 2017; 147; 33-42.

20. Nkuize M, De Wit S, Muls V, Arvanitakis M, Buset M. Upper gastrointestinal endoscopic findings in the era of highly active antiretroviral therapy. HIV Med. 2010; 11; 412-417.

21. Pappas PG, Kauffman CA, Andes DR et al. Clinical practice guideline for the management of candidiasis: 2016 update by the Infectious Diseases Society of America. Clin. Infect. Dis. 2016; 62; 409-417.

22. Finlay PM, Richardson MD, Robertson AG. A comparative study of the efficacy of fluconazole and amphotericin B in the treatment of oropharyngeal candidosis in patients undergoing radiotherapy for head and neck tumours. Br. J. Oral Maxillofac. Surg. 1996; 34; 23-25.

23. Krause DS, Chapman SW, Kett DH et al. Anidulafungin versus fluconazole for invasive candidiasis. N. Engl. J. Med. 2007; 14; 2472-2482.

24. Pons V, Greenspan D, Lozada-Nur F et al. Oropharyngeal candidiasis in patients with AIDS: randomized comparison of fluconazole versus nystatin oral suspensions. Clin. Infect. Dis. 1997; 24; 1204-1207. 
25. Benson CA, Kaplan JE, Masur H, Pau A, Holmes KK; CDC; National Institutes of Health; Infectious Diseases Society of America. Treating opportunistic infections among HIV-infected adults and adolescents: recommendations from $\mathrm{CDC}$, the National Institutes of Health, and the HIV Medicine Association/Infectious Diseases Society of America. MMWR Recomm. Rep. 2004; 53; 1-112.

26. Darouiche RO. Oropharyngeal and esophageal candidiasis in immunocompromised patients: treatment issues. Clin. Infect. Dis. 1998; 26; 273-274.

27. Min YW, Kim E, Son HJ, Kim JJ, Rhee PL. Antifungal treatment is not required for immunocompetent individuals with asymptomatic esophageal candidiasis. Medicine (Baltimore) 2015; 94; e1969.

28. Lee SP, Sung IK, Kim JH, Lee SY, Park HS, Shim CS. The clinical course of asymptomatic esophageal candidiasis incidentally diagnosed in general health inspection. Scand. J. Gastroenterol. 2015; 50; 1444-1450.

29. Hoversten P, Otaki F, Katzka DA. Course of esophageal candidiasis and outcomes of patients at a single center. Clin. Gastroenterol. Hepatol. 2019; 17; 200-202.

30. Demir D, Dołanavşargil B, Sarsik B, Sezak M, Tunçyürek M. Is it possible to diagnose infectious oesophagitis without seeing the causative organism? A histopathological study. Turk. J. Gastroenterol. 2014; 25; 481-487.

31. Wilcox CM, Schwartz DA. Endoscopic-pathologic correlates of Candida esophagitis in acquired immunodeficiency syndrome. Dig. Dis. Sci. 1996; 41; 1337-1345.

32. Martin IW, Atkinson AE, Liu X, Suriawinata AA, Lefferts JA, Lisovsky M. Mucosal inflammation in Candida esophagitis has distinctive features that may be helpful diagnostically. Mod. Pathol. 2018; 31; 1653-1660. 